\title{
THE SERUM ANTISTREPTOLYSIN TITER IN ACUTE GLOMERULONEPHRITIS
}

\author{
By JOHN D. LYTTLE, DAVID SEEGAL, EMILY NICHOLS LOEB, \\ AND ELIZABETH L. JOST \\ (From the Departments of Medicine and Pediatrics, College of Physicians and Surgeons, \\ Columbia University, the Babies Hospital, the Presbyterian Hospital, and the Research \\ Division for Chronic Diseases, Department of Hospitals, New York City)
}

(Received for publication April 28, 1938)

This work on the level of antistreptolysin titer in the serum of patients with acute glomerulonephritis is part of a study being conducted by the Departments of Medicine and Pediatrics on the rôle of infection in acute and chronic glomerulonephritis. The literature and texts list the most heterogeneous types of infection (influenza, diphtheria, measles, the common cold, sore throat, exposure, osteomyelitis, " pregnancy," intestinal catarrh, pyodermia, etc.), as the prodromal episode in acute glomerulonephritis. For this reason and because at the time the patients are first observed (at the onset of the nephritis) the clinical and bacteriological evidence of the preceding infection may be inadequate, it seemed desirable to obtain more specific evidence on the character of the infection which precedes the nephritis. A preliminary study (1) in 1933 showed that of 22 patients with acute glomerulonephritis the sera of 20 had a definite increase in antistreptolysin titer. The present report is a more complete study of this antibody in a larger group of patients observed over a period of four years.

In 1932, Todd (2) demonstrated that the sera of animals immunized with the hemolysin of the Streptococcus hemolyticus developed a significant amount of an antibody inhibiting the activity of this hemolysin. This antibody had been called antistreptohemolysin or antistreptolysin. The sera of animals immunized to a variety of other bacterial antigens did not contain appreciable quantities of this antibody. Later Todd (2), Coburn and Pauli (3), Griffiths (4), Myers and Keefer (5), Lippard and Johnson (6), Wilson, Wheeler, and Leask (7), Blair and Hallman (8), Longcope (9) and others have investigated and reported the antistreptolysin content of the sera in normal individuals and in patients with infections resulting from Streptococcus hemolyticus and other organisms.
A description of the technique used in determining the serum antistreptolysin is found in the Appendix of Todd's publication (2). The preparation of the medium now used to produce the streptolysin is that outlined by Todd and Hewitt (10), with the exception that beef heart is used instead of horse meat. In the titration of the streptolysin, however, we follow the method of Hodge and Swift (11) and determine its combining unit. For this method we use Dr. Todd's standard antistreptolysin horse globulin which he kindly furnished us. In the routine test this globulin (diluted so that $1.0 \mathrm{cc} .=20,000$ units) and normal human sera are run regularly as controls.

\section{The normal antistreptolysin titer}

There is general agreement that the antistreptolysin level in individuals who have been free of hemolytic streptococcus infection is less than 100 units. Coburn and Pauli (3) found that of 146 normal individuals, 75 per cent had a titer of 100 units or less; 20 per cent had between 100 and 200 units; and 5 per cent had 200 units or more. Longcope (9) found that of 55 normal individuals the titer was between 25 and 50 units in 75 per cent and was above 100 units in only 1 individual. Although Wilson, Wheeler, and Leask (7) conclude that " a rise in antistreptolysin titer of the serum is not conclusive evidence of streptococcal respiratory infection," among other workers there is general agreement that following infections with hemolytic streptococcus, the antistreptolysin titer rises and that high titers may be maintained for some time after the infection has subsided. The rise in titer may be moderate in degree and of brief duration, and may be shown only when determinations are made for a period before and after an infection in order to obtain the natural or basal level. In other words, the antistreptolysin 
titer of an individual taken at random may be difficult to interpret, but if serial studies are made, interpretation is more accurate and the significance of moderate elevation of titer is clearer. For our purpose we have considered an antistreptolysin titer of 125 units or more as an evidence of recent infection with hemolytic streptococcus if previous or subsequent determinations show the level to be lower.

\section{Clinical and bacteriological data}

This report is based on a study of 116 consecutive and unselected cases of acute glomerulonephritis seen at the Babies Hospital and Presbyterian Hospital from March 1933 through May 1937. The diagnosis of acute glomerulonephritis in our patients was based on the presence of the commonly accepted clinical and laboratory findings for this disease. Patients with acute pyelonephritis, subacute bacterial endocarditis, or obscure forms of acute nephritis are not included. On the clinical side, certain points should be made clear. There are 95 children under 13 years of age and 21 adults in our series. Although acute nephritis is more common in childhood, if one studies the condition only in children or only in adults one does not get a complete picture of the disease. Our series embraces the characteristic age distribution in acute nephritis. Males predominate 2 to 1 in the series. It is quite probable that in the majority of attacks of acute nephritis the disease is so mild tha: the physician is not consulted. Many of our patients were admitted to the hospital because of the severity of an infection and subsequently routine examination showed the presence of nephritis. The fact that we have been dealing either with the more severe forms of nephritis or with the mild type of nephritis occurring in severe infections must be considered in interpreting the data. The majority of patients showed definite clinical and bacteriological evidence of hemolytic streptococcal infection but many gave only a vague or negative history of preceding infection. It must be remembered also that even if the patient is observed at the onset of the nephritis the infection is believed to have preceded the nephritis by from 10 to 30 days and the direct evidence for this infection may be inadequate at the time the patient is first observed.
The great majority of the patients in this series had a history or showed evidence of infection of the upper respiratory tract preceding or accompanying the onset of acute nephritis. In 104 cases where data were adequte, the infection was located in the upper respiratory tract or its appendages. In 12 of the 116 cases the data were insufficient to make a clinical diagnosis. The clinical diagnoses are shown in Table I.

TABLE I

Clinical diagnoses

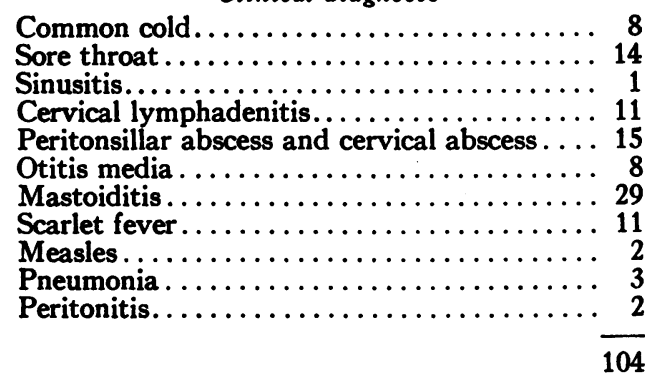

In 6 of these 104 cases no cultures were made. In 46 patients with upper respiratory infection, throat cultures were negative for hemolytic streptococcus in 18 and positive in 28 . The possibility of an antecedent hemolytic streptococcal infection in the patients showing negative cultures on admission is not excluded since cultures were taken anywhere from 2 to 6 weeks after the onset of infection. In 7 of the 18 patients with negative throat cultures a culture taken from the excised tonsils during convalescence showed hemolytic streptococcus. Of 51 patients with an active focus of infection (peritonsillar abscess, mastoiditis, etc.), 47 had a positive culture for hemolytic streptococcus. The 2 patients with measles and 2 of the 3 patients with prieumonia had positive throat cultures for hemolytic streptococcus. In summary, 83 or 71.5 per cent of the 116 cases had bacteriological evidence of infection with hemolytic streptococcus while 33 or 28.5 per cent had negative bacteriological evidence of hemolytic streptococcal infection.

Though all patients that were observed in the acute stages are included for a general survey, we have selected for more careful analysis groups of cases who were seen early in the course of the disease and who were followed through to complete healing or to the development of chronic 
glomerulonephritis. In these groups more complete clinical and immunological data make possible an attempt to discover any correlation between the immunological data and the clinical course.

The maximum antistreptolysin titer during the acute stage of glomerulonephritis

Figure 1 presents the maximum titer of antistreptolysin found in 116 consecutive cases of

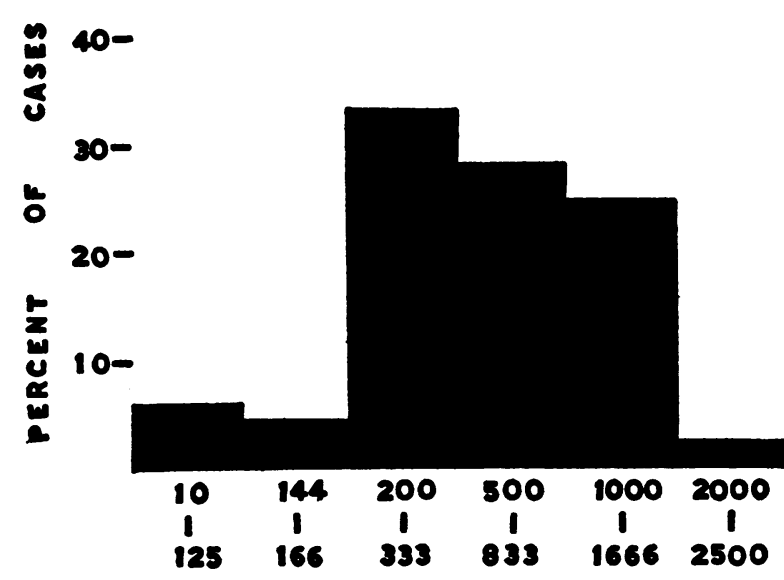

ANTISTREPTOLYSIN TITER IN UNITS

Fig. 1. Maximum Antistreptolysin Titer in 116 Cases of Acute Glomerulonephritts

acute glomerulonephritis. The maximum titer is usually reached in the first few weeks of the disease, which has its onset about 2 weeks following the acute infection. The highest antistreptolysin titer in the first 40 days after the onset of the nephritis is shown in each case. It is apparent that in 94 per cent of 116 cases the antistreptolysin titer was above 125 units and in 27 per cent the titers were between 1000 and 2500 units. Since we consider 125 units to be the upper normal level of antistreptolysin, this lends further support to the results of direct culture just quoted and indicates that the great majority of patients with acute glomerulonephritis have had a recent hemolytic streptococcal infection.

There were 7 patients ( 5 children, 2 adults) whose maximum antistreptolysin titer was 125 units or less. In 2 children determinations were not made until the 35th and 38th day of the nephritis and corresponidingly later after the acute infection. Hence the rise so commonly observed in the first weeks of the disease may have been missed in these cases. In both these patients the maximum antistreptolysin was 125 units and subsequent determinations after the nephritis had healed showed the basal level to be between 55 and 62 units in one patient and 20 and 33 units in the other. These later observations suggest that the 125 unit level represented a significant increase in antistreptolysin titer for both patients. In another child who had a history of sore throat and cervical lymphadenitis preceding the nephritis, titers were determined frequently from the 8th day after the onset of the nephritis, yet the highest antistreptolysin titer found was 125 units. There was no bacteriological evidence of hemolytic streptococcal infection but minimal urinary changes persisted for one year, and for 15 months after onset the antistreptolysin titer remained at 100 to 125 units. It was of interest, however, that at 2 years and at 3 years after the onset of the nephritis the antistreptolysin titers were 72 and 71 units. In the fourth patient a mild acute nephritis followed an operation for ruptured appendix and peritonitis. Colon bacilli and hemolytic streptococci were cultured from the peritoneal fluid at operation, yet four antistreptolysin determinations during the acute stages of the nephritis showed values of less than 10 units. We have no explanation for the failure of the antistreptolysin titer to rise in this patient. In a fifth instance a 12-year-old boy gave a history of a sore throat followed in 11 days by hematuria and edema and accompanied by a recrudescence of the sore throat and cervical lymphadenitis. He was first observed on the 8th day after the onset of the nephritis. At this time, throat culture showed pneumococci predominating, and the antistreptolysin titer was 100 units. On the $22 \mathrm{~d}$ day the antistreptolysin titer was 83 units. Seven antistreptolysin determinations made in the next 2 months showed titers of 62 or 71 units. Bacteriologically, no hemolytic streptococcal infection was ever proven to exist in this patient. One can postulate that the initial titer of 100 units is a rise over the subsequent basal level and may represent the patient's response to hemolytic streptococcal infection. It is also possible that hemolytic streptococcal infection had nothing to do with this case of nephritis.

In the adult group two patients failed to show 
any rise in antistreptolysin titer. Case G. R., a 38-year-old female, developed acute glomerulonephritis 21 days following lobar pneumonia resulting from Pneumococcus Type III. At no time was there clinical or bacteriological evidence of hemolytic streptococcal infection. Repeated antistreptolysin determinations during the acute stage and for 15 months after the onset of the nephritis showed titers of 35,55 , and 62 units. The nephritis here may have resulted from a pneumococcal infection. The second adult, J. W., 31-year-old male, had a sore throat followed in 8 days by smoky urine, edema, and hypertension. He was first observed on the 10th day after onset of nephritis when the antistreptolysin titer was 83 units. At this time, throat cultures were negative for hemolytic streptococcus and there was no evidence of any other focus of infection. He developed chronic glomerulonephritis, and 11 antistreptolysin titers in the course of the first year were 100 or 111 units. No hemolytic streptococcal infection was proven in this patient and no significant rise in antistreptolysin titer was observed.

Maximum antistreptolysin titer and sex. Our figures fail to show any significant differences between the sexes in their ability to develop antistreptolysin in response to hemolytic streptococcal infection.

Maximum antistreptolysin titer and age. Since the adult group is small in relation to the number of children, it is difficult to say whether certain apparent correlations of antistreptolysin level with age are significant. Of 21 adult cases, 5 had maximum titers of 166 or less, whereas only 6 of 95 children had maximum titers of 166 or less. Of 13 children under 2 years of age, 8 developed maximum titers of 500 units or higher. This is not in agreement with the experience of Lippard and Johnson (6) who found that the majority of young infants who recovered from hemolytic streptococcal infection without developing nephritis did not show striking increases in antistreptolysin titer.

Maximum antistreptolysin titer and infection. The most striking correlation between the maximum antistreptolysin titer and the various clinical features exhibited by the patients in this series was that in relation to the severity of the preceding infection. It has been previously stated that only one type of infection has been described for each patient. For instance, if a patient was shown to have had an acute pharyngitis, otitis media, and mastoiditis, the most severe of these conditions was the one used to describe the prodromal infection for that patient. Table II illustrates the relationship between the maximum antistreptolysin and the type of infection.

TABLE II

Relation of maximum antistreptolysin titer and type of infection

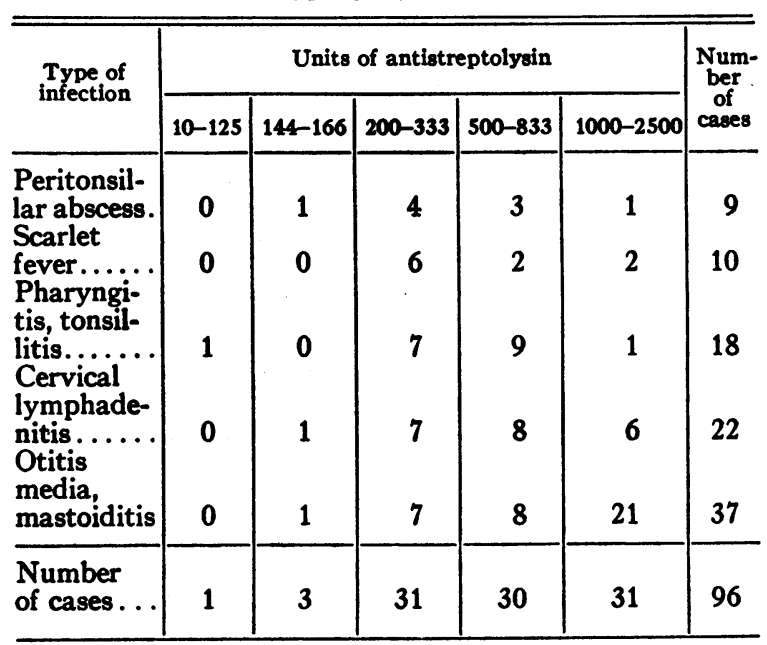

In the group with low titers, the diagnosis otitis media, cervical lymphadenitis, and peritonsillar abscess occurs only once. In the group with a moderate elevation of the antistreptolysin value, the cases of otitis media and mastoid disease, cervical lymphadenitis and scarlet fever are equally divided. In the group with titers of 500 to 833 units, otitis media and mastoiditis, cervical lymphadenitis and peritonsillar abscess account for two-thirds of the cases; but in the group with high titers (1000 to 2500 units) these diagnoses account for 90 per cent of the cases. It should be noted that these infections are frequently cumulative, that is, a patient with mastoiditis may be assumed to have had a pharyngitis and cervical lymphadenitis before the otitis media and mastoiditis developed.

Maximum antistreptolysin titer and degree of infection and degree of nephritis. An attempt was made to correlate the severity of the infection and the severity of the nephritis with the maximum antistreptolysin titer in 101 patients. 
Estimates as to the severity of infection and of nephritis are of necessity only gross. Uncomplicated scarlet fever, pharyngitis, and a transient cervical lymphadenitis were regarded as mild infections. Peritonsillar abscess, cervical lymphadenitis which progressed to abscess formation and mastoiditis were looked upon as severe infections. The severity of the nephritis was gauged by the degree and duration of the urinary changes, hypertension, edema, and nitrogen retention. Table III shows the data in this regard.

\section{TABLE III}

Maximum antistreptolysin titer in 101 patients in relation to severity of infection and nephritis

\begin{tabular}{|c|c|c|c|c|c|c|c|}
\hline \multirow{2}{*}{ Severity of infection } & \multicolumn{6}{|c|}{ Units of antistreptolysin } & \multirow{2}{*}{$\begin{array}{c}\text { Num } \\
\text { ber } \\
\text { of } \\
\text { cases }\end{array}$} \\
\hline & $\begin{array}{l}10- \\
125\end{array}$ & $\begin{array}{l}144- \\
166\end{array}$ & $\begin{array}{l}200- \\
333\end{array}$ & \begin{tabular}{|l|}
$500-$ \\
833
\end{tabular} & $\begin{array}{l}1000 \\
1666\end{array}$ & $2000-$ & \\
\hline \multirow{2}{*}{$\begin{array}{l}\text { Group } 1 \\
\text { Severe infection } \\
\text { with mild nephritis } \\
\text { Group } 2 \\
\text { Severe infection } \\
\text { with severe neph- } \\
\text { ritis.............. }\end{array}$} & \multirow{2}{*}{$\begin{array}{l}1 \\
0\end{array}$} & 2 & 12 & 11 & 22 & 3 & 51 \\
\hline & & 1 & 3 & 4 & 4 & 0 & 12 \\
\hline $\begin{array}{l}\text { Group } 3 \\
\text { Mild infection } \\
\text { with mild nephritis }\end{array}$ & 2 & 0 & 6 & 8 & 1 & 0 & 17 \\
\hline \multirow[t]{2}{*}{$\begin{array}{l}\text { Group } 4 \\
\text { Mild infection } \\
\text { with severe neph- } \\
\text { ritis............ }\end{array}$} & 2 & 1 & 9 & 7 & 2 & 0 & 21 \\
\hline & & & & & & & 101 \\
\hline
\end{tabular}

In the first group are tabulated the results in those patients with a severe infection and a mild nephritis. Half of the 101 patients are found to be in this group. The antistreptolysin titer was elevated in all but one patient, with only slight elevation in two patients. From what has been said one would expect to find the largest number of high titers in this group, and this is so. Of the 51 patients, 50 per cent showed maximum antistreptolysin titers over 1000 units and 70 per cent exhibited values over 500 units. It is of interest that none of the patients in this group developed chronic nephritis.

In Group 2 are tabulated the figures from 12 patients with a severe infection and a severe nephritis. The results are similar to those in the first group, over half having titers of 500 units or higher. But in this group are 3 of the $8 \mathrm{pa}$ tients who developed chronic nephritis. One of these patients had mastoiditis and two had a peritonsillar abscess, infections which usually give a very high antistreptolysin titer, yet in these patients the titers were 250,144, and 833 units respectively. However, it cannot be said that the failure to develop a high titer following a severe infection points to the probability of the subsequent development of chronic nephritis, for it is seen in Group 1 that 15 patients with severe infections did not reach high levels yet the nephritis healed promptly.

In Group 3 are the antistreptolysin values of 17 patients with mild infection and mild nephritis. The nephritis healed promptly in all cases. In all but two patients the antistreptolysin titers were above normal. In Group 4 are the figures for 21 patients with mild infection and severe nephritis including 5 patients who developed chronic nephritis. The distribution of maximum antistreptolysin titers is practically identical in these two groups.

From the data presented, it appears that severe nephritis is not usually accompanied by extremely high antistreptolysin titers. Of 32 patients with antistreptolysin titers of 1000 units or higher only 6 or 18.7 per cent had severe nephritis and none developed chronic nephritis.

Maximum antistreptolysin titer and duration of nephritis. Healing occurred in 108 of the 116 cases within 1 year. No correlation could be established between the maximum antistreptolysin response and the rapidity with which healing occurred or the development of chronic nephritis. Of the 8 patients who progressed to chronic nephritis 5 had a mild infection, with normal antistreptolysin titers in 2 and moderate elevation $(144,200,714$ units) in 3 patients. Three had a severe infection with only moderate elevation of antistreptolysin titer in 2 (144, 250 units) and a rise to 833 units in one patient. It is obvious that the number of patients who developed chronic nephritis under observation is too small to warrant conclusions, but the data available suggest that low antistreptolysin titers in acute nephritis do not indicate that chronic nephritis will develop or that the development of chronic nephritis is always associated with low antistreptolysin titers. 


\section{COMMENT}

Longcope (9) studied 36 adult patients during the acute stage of hemorrhagic nephritis. Twenty-three patients or 64 per cent showed antistreptolysin titers above 125 units. The highest titer observed was 500 units, found in 2 patients. The type of infection accompanying the nephritis was quite different in Longcope's series from ours. The deep infections such as mastoiditis and cervical lymphadenitis which occurred so frequently in our series where children predominate are not found in the group observed in Baltimore. This may account for the smaller percentage of cases showing antistreptolysin elevation and the lack of very high antistreptolysin titers.

Careful study of our clinical and immunological data indicate that in the acute stages of glomerulonephritis the maximum antistreptolysin titer is (1) not related to age or sex, (2) has no relation to the severity or duration of the nephritis, but (3) is definitely related to the type and severity of the acute infection which precedes or accompanies the acute nephritis.

The data presented here establish the fact that in spite of the heterogeneous group of prodromal infections observed or the unsatisfactory history and clinical evidence of the preceding infection in many cases, 94 per cent of 116 consecutive cases of acute glomerulonephritis show specific immunological evidence of having had a recent hemolytic streptococcal infection.

\section{The titer of antistreptolysin following acute glomerulonephritis}

The diagram in Figure 2 shows the variations in immune response during the two years following the onset of acute nephritis. This diagram was made by using only the highest antistreptolysin titer found for each patient in each of the first twelve months after onset. For the second year after the onset, all the antistreptolysin determinations on each patient studied are included. The majority of the 63 patients in this group had from 4 to 8 antistreptolysin determinations during this 2 -year period.

The diagram shows that in the second month the number of normal titers begins to increase and the number of high titers decreases. In the second year after onset the titers in 75 per cent

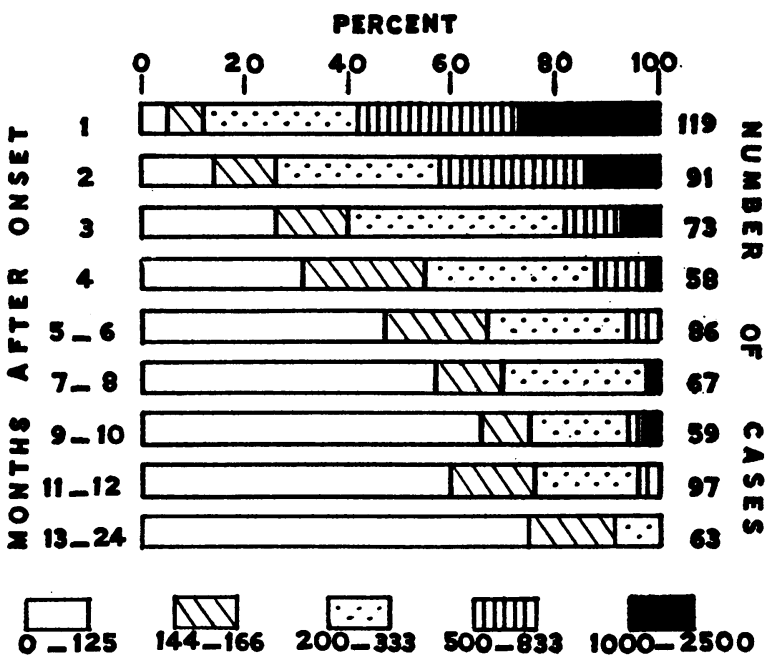

Fig. 2. Titer of Antistreptolysin Following Acute GLOMERULONEPHRITIS

of the patients are normal and 25 per cent have titers from 144 to 333 units. At this time the nephritis had healed in all but 8 patients. This period serves as a control for the group and these figures are in good agreement with the control group of Coburn and Pauli in New York City who found that 75 per cent of 146 individuals had titers of 100 units or below.

In Figure 3 are presented curves to show the variations in antistreptolysin titer in the first year after the onset of nephritis. In 71 patients determinations were made frequently enough so that a significant curve could be made. These curves fall roughly into 7 groups; two curves are shown as representative of each group.

Group A. Thirteen of the 71 patients showed this type of response. Five of the 8 patients who developed chronic nephritis were in this group. The significance of this will be discussed later.

Group B. Thirteen patients showed this type of curve, i.e., a moderate initial rise and a prompt fall to normal levels. All except one individual recovered completely.

Group C. Ten patients showed this type of curve, an initial rise to 500 units with a tendency to moderate elevation of titer at the end of the first year. All these patients recovered.

Group D. Twelve patients showed this type of response, a high initial rise ( 800 units) with normal titers by the third month. Two patients who 

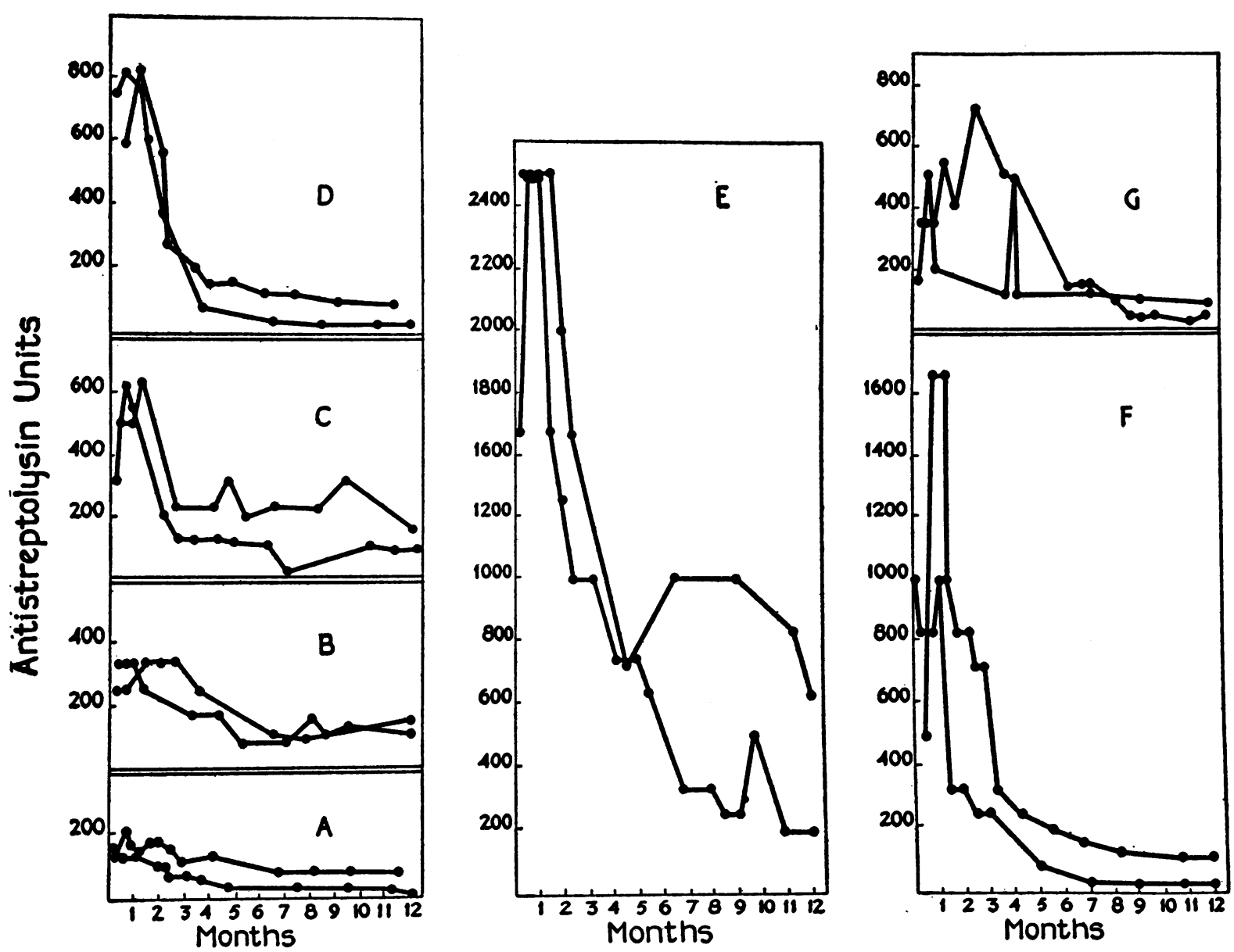

Fig. 3. Variations in Antistreptolysin Titer in the First Year of Acute Nephitis.

developed chronic nephritis showed this type of response.

Group E. Three patients showed extremely high initial titers with a slow fall toward normal levels but at the end of the first year the titers were still abnormally high.

Group F. Thirteen patients showed extremely high initial titers with normal titers after the 6th month. All recovered.

Group G. Seven patients showed either a rising titer in convalescence or a secondary rise after the initial rise and fall in titers. In all these patients there was an exacerbation of the infection or a reinfection by hemolytic streptococcus.

\section{DISCUSSION}

The great majority of individuals who have hemolytic streptococcal infection followed by an attack of acute glomerulonephritis develop a sig- nificant rise in antistreptolysin titer. But this response is known to occur in individuals in whom hemolytic streptococcal infection is not followed by acute glomerulonephritis.

The maximum antistreptolysin titer is present at the onset or during the first few weeks of the attack of acute nephritis but the significance of this fact is not apparent. The maximum rise in antistreptolysin titer may be of all degrees and the clinical findings in the patients who developed extremely high antistreptolysin titers are not different from those who developed a moderate or intermediate rise in antistreptolysin titer.

The fact that 5 of the 8 patients who developed chronic nephritis showed only moderate elevation of antistreptolysin titer (Group A, Figure 3) is interesting.

The value of $x^{2}$ calculated from Table IV using Yates' correction is 8.676 . The value re- 
TABLE IV

Relation of antistreptolysin titer and the development of chronic nephritis

\begin{tabular}{l|c|c|c}
\hline \hline & $\begin{array}{c}\text { Moderate elevation } \\
\text { of antistreptolysin } \\
\text { titer }\end{array}$ & $\begin{array}{c}\text { Intermediate and } \\
\text { high elevation of } \\
\text { antistreptolysin titer }\end{array}$ & Total \\
\hline $\begin{array}{c}\text { Chronic } \\
\text { nephritis. }\end{array}$ & 5 & 3 & 8 \\
$\begin{array}{c}\text { Healed } \\
\text { nephritis.. } \\
\text { Total....... }\end{array}$ & 8 & 55 & 63 \\
\hline
\end{tabular}

quired to demonstrate significant $(P=0.01)$ deviation from random sampling $=6.635$. While these figures are statistically significant there are too many other factors to be considered in the evolution of chronic glomerulonephritis and the number of cases is too small to make possible a definite conclusion. Further study may throw more light on this point.

In the majority of patients the antistreptolysin titer begins to fall in the first or second month of the disease and in half the patients the antistreptolysin titer is normal by the 6th month. In this period the nephritis begins to improve clinically as measured by the disappearance of hypertension and edema, diminution in albuminuria and hematuria, and by the return of normal kidney function. But this finding may be coincidental rather than correlative since analysis of the data accumulated in the 2-year period after the onset of the nephritis shows no correlation between the rate at which the antistreptolysin titer returns to normal and the clinical changes in the patient. In the second year after the onset of the nephritis when 108 of the 116 patients were healed, the antistreptolysin titer was normal in 75 per cent with 25 per cent of the patients showing a moderate elevation (144 to 333 units).

It is well known that antibody responses to various infections may persist for a long time after the acute infection has subsided. That this is true also of antistreptolysin is shown in the charts. Recently Todd expressed the opinion based on animal work that the persistence of high antistreptolysin titers in convalescence signifies persistence of the infection. A study of our cases indicates that this is probably true in hemolytic streptococcal infection in man. In all 31 of our patients in whom high titers either persisted or recurred after the initial rise and fall there was definite clinical or bacteriological evidence of the persistence or recurrerice of infection. These patients were carefully studied for information as to the effect on the nephritis of the persistent or recurrent infection. In only 10 of the 31 patients could it be said that the infection had an adverse effect on the nephritis. This effect was shown in some cases by an increase in hematuria and albuminuria and in others by the persistence of well-marked hematuria and albuminuria. It is believed by some workers that persistence of the infection or the recurrence of infection in convalescence from nephritis is associated with persistence or exacerbation of the nephritis. This may be true in some cases but it is certainly not the rule. Longcope states that when "the disease progressed to a chronic stage the antistreptolysin titer remained at a high level in a fair proportion of instances." The rôle of hemolytic streptococcal infection on the course of chronic nephritis is to be considered elsewhere (12) but it can be said here that, in this series, in the 8 patients who progressed to chronic nephritis the level of antistreptolysin was normal in all at 6 months and has remained normal during the subsequent period of observation.

\section{CONCLUSIONS}

1. In $\mathbf{1 1 6}$ consecutive cases of acute glomerulonephritis the bacteriological data indicate that 71.5 per cent had a prodromal hemolytic streptococcal infection, and the immunological data show that 94 per cent had had a recent hemolytic streptococcal infection.

2. The height and duration of the antistreptolysin titer in patients with acute glomerulonephritis appear to be related to the severity, persistence, or recurrence of the hemolytic streptococcal infection.

3. Analysis of the immunological and clinical data in the present study does not show any significant correlation between the height and duration of the antistreptolysin response and the severity or duration of the acute attack of nephritis or the tendency to develop chronic nephritis.

4. There is a wide variation in the curve of antistreptolysin response constructed over a long period of time. The form of the curves has no relation to the severity or duration of acute ne- 
phritis or to the tendency to develop chronic nephritis.

\section{BIBLIOGRAPHY}

1. Seegal, D., and Lyttle, John D., Antistreptolysin titre of the serum in acute glomerular nephritis. Proc. Soc. Exper. Biol. and Med., 1933, 31, 211.

2. Todd, E. W., Antigenic streptococcal hemolysin. J. Exper. Med., 1932, 55, 267.

Todd, E. W., Antihaemolysin titres in haemolytic streptococcal infections and their significance in rheumatic fever. Brit. J. Exper. Path., 1932, 13, 248.

3. Coburn, A. F., and Pauli, Ruth H., Studies on the immune response of the rheumatic subject and its relationship to activity of the rheumatic process. VI. The significance of the rise of antistreptolysin level in the development of rheumatic activity. J. Clin. Invest., 1935, 14, 769.

4. Griffiths, G. J., Antihaemolysin titres in chronic rheumatic and allied diseases. Lancet, 1934, 2, 251.

5. Myers, W. K., and Keefer, C. S., Antistreptolysin content of the blood serum in rheumatic fever and rheumatoid arthritis. J. Clin. Invest., 1934, $13,155$.

6. Lippard, V. W., and Johnson, P., Beta hemolytic streptococcic infection in infancy and in childhood. I. Antifibrinolysin and antistreptolysin response. Am. J. Dis. Child., 1935, 49, 1411.
7. Wilson, May G., Wheeler, G. W., and Leask, M. M., The relation of upper respiratory infections to rheumatic fever in children. II. Antihemolysin titres in respiratory infections and their significance in rheumatic fever in children. J. Clin. Invest., 1935, 14, 333.

8. Blair, J. E., and Hallman, F. A., Streptococcal agglutinins and antistreptolysins in rheumatoid (atrophic) arthritis. J. Clin. Invest., 1935, 14, 505.

9. Longcope, W. T., Studies of the variations in the antistreptolysin titer of the blood serum from patients with hemorrhagic nephritis. I. Control observations on healthy individuals and patients suffering from diseases other than streptococcal infections. J. Clin. Invest., 1936, 15, 269.

II. Observations on patients suffering from streptococcal infections, rheumatic fever and acute and chronic hemorrhagic nephritis. J. Clin. Invest., 1936, 15, 277.

10. Todd, E. W., and Hewitt, L. F., A new culture medium for the production of antigenic streptococcal hemolysin. J. Path. and Bact., 1932, 35, 973.

11. Hodge, B. E., and Swift, H. F., Varying hemolytic and constant combining capacity of streptolysins; influence on testing for antistreptolysins. J. Exper. Med., 1933, 58, 277.

12. Seegal, D., Lyttle, J. D., Loeb, E. N., and Jost, E. L., The rôle of hemolytic streptococcal infection in chronic glomerulonephritis. (Unpublished observations.) 